\title{
Successful combined transpapillary and transmural management of a large biloma and bile duct injury: A case report and review of literature
}

\author{
Hemanta Kumar Nayak, Vivek Anand Saraswat, Samir Mohindra, Atul Sharma, Uday C. Ghoshal
}

Department of Gastroenterology, Sanjay Gandhi Postgraduate Institute of Medical Sciences, Lucknow, Uttar Pradesh, India

$\begin{array}{ll}\text { Abstract } & \begin{array}{l}\text { Here, we report a patient with bile duct injury (BDI) following open cholecystectomy, who developed } \\ \text { a very large biloma, causing duodenal and biliary obstruction, and also had a biliary stricture at the } \\ \text { site of BDI. We successfully managed the patient by endoscopic biloma-gastrostomy with biliary } \\ \text { stenting that resulted in resolution of the biloma and aggressive endoscopic management of the } \\ \text { biliary stricture with stent bundles till resolution. Pertaining this case to be the one with largest } \\ \text { biloma in the literature (approximately } 6.5 \text { L), which developed following open cholecystectomy } \\ \text { that resulted in biliary stricture following injury to BD. We successfully managed the patient by } \\ \text { endoscopic biloma-gastric stenting and an aggressive endoscopic management of biliary stricture. }\end{array} \\ \text { Key words } & \text { Bile duct injury, biliary stricture, biloma }\end{array}$

\section{Introduction}

A biloma is defined as an encapsulated collection of bile outside the biliary tree. Biloma can result either from iatrogenic injury (surgery, percutaneous trans-hepatic interventions) or abdominal trauma. ${ }^{[1]}$ Most patients with a small biloma are asymptomatic, and the collection often resolves spontaneously. Rarely, it may present with abdominal pain, fever, vomiting, gastric outlet obstruction, and abscess formation. Such symptomatic bilomas are usually large or associated with bile ascites and usually need intervention in the form of either percutaneous aspiration under radiological guidance or surgical drainage. ${ }^{[2]}$

\section{Case Report}

A 29-year-old male patient presented with jaundice, progressive

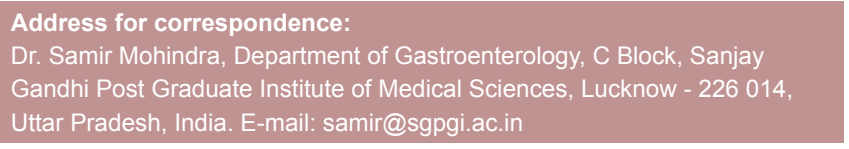

\begin{tabular}{|l|c|}
\hline \multicolumn{2}{|c|}{ Access this article online } \\
\hline \multirow{2}{*}{$\begin{array}{l}\text { Website: } \\
\text { www.jdeonline.in }\end{array}$} & Quick Response Code \\
\hline DOI: & \\
10.4103/0976-5042.165710 & \\
\hline
\end{tabular}

abdominal distension, and fever of 6 weeks duration. He had undergone open cholecystectomy in a community hospital for symptomatic cholelithiasis 12 weeks prior to admission. Though surgery only lasted $40 \mathrm{~min}$ and was reported to be uneventful, symptoms developed after removal of the right subcostal drain on the $4^{\text {th }}$ postoperative day. At admission, he was febrile and icteric. Abdominal examination revealed asymmetrical swelling and tenderness in the right upper quadrant.

Investigations revealed that hemoglobin was $13 \mathrm{~g} / \mathrm{dL}$ (normal $11.0-15.0$ ), total leukocyte count $16,000 / \mathrm{mm}^{3}$ (normal 4000 11,000 ) with left shift, platelet count $270 \times 10^{9} / \mathrm{L}$ (normal $150-400 \times 10^{9}$ ). His serum bilirubin was $6.5 \mathrm{mg} / \mathrm{dL}$ (normal $0.3-1.30$ ), predominantly conjugated, alkaline phosphatase was $400 \mathrm{IU} / \mathrm{mL}$ (normal range 40-150). Abdominal ultrasonography and computed tomography (CT) showed a very large collection in the lesser sac (about $6 \mathrm{~L}$ ) and a smaller collection $(300 \mathrm{~mL})$ in the left subhepatic space. These collections were compressing the common bile duct (CBD) leading to mild intra-hepatic biliary radicle dilation (IHBRD)

This is an open access article distributed under the terms of the Creative Commons Attribution-NonCommercial-ShareAlike 3.0 License, which allows others to remix, tweak, and build upon the work non-commercially, as long as the author is credited and the new creations are licensed under the identical terms.

For reprints contact: reprints@medknow.com

How to cite this article: Nayak HK, Saraswat VA, Mohindra S, Sharma A Ghoshal UC. Successful combined transpapillary and transmural management of a large biloma and bile duct injury: A case report and review of literature. J Dig Endosc 2015;6:119-22. 
[Figure 1]. Needle aspiration confirmed it to be a biloma. Magnetic resonance cholangiopancreatography (MRCP) revealed separation of right anterior sectoral (RAS), right posterior sectoral (RPS) and left hepatic ductal systems (LHD), and nonvisualisation of the CBD [Figure 2a].

During duodenoscopy, a smooth bulge was seen on greater curvature in the body stomach, suggesting extrinsic compression [Figure 3a]. A smaller bulge was also seen on the lesser curve. The gastric wall was punctured over the bulge with a needle knife, bile was aspirated and a $0.038^{\prime \prime}$ guide wire passed into the biloma. The track was dilated with a $12 \mathrm{~mm}$ controlled radial expansion (CRE) balloon and a 10 French, $7 \mathrm{~cm}$ long double-pigtail stent and a 10 French endoscopic naso-cystic drain (ENCD) were placed, which drained bile [Figure 3b]. Approximately $6.5 \mathrm{~L}$ of bile was aspirated on the table during the procedure. Subsequently, bilirubin level in the aspirated fluid was $6.0 \mathrm{mg} / \mathrm{dL}$, which was consistent with a biloma.

Endoscopic sphincterotomy (ES) was performed and the cholangiogram showed a leak in the subhilar region and hilar stricture with separation of right anterior, right posterior and left systems (strasberg Type 5 injury) [Figure $4 a$ and b]. A single 10 French, $10 \mathrm{~cm}$ long plastic stent was placed across the leak to the RAS [Figure 4c]. Bile drainage from the ENCD gradually diminished and resolved over the next 7 days. The ENCD was removed and the patient was discharged. Intra-venous antibiotic (injection ceftriaxone $2 \mathrm{~g}$ twice a day) was administered for 14 days.

Repeat duodenoscopy, after 1 month revealed resolved prominent bulges on the posterior wall and the lesser curvature of the stomach. MRCP performed after stent removal revealed trifurcation at the primary biliary confluence with IHBRD and narrowing of the proximal common hepatic duct (CHD) and LHD [Figure 2b]. At endoscopic retrograde cholangiogram (ERC), the cholangiogram confirmed a complex biliary stricture (Type 4 benign biliary strictures), which were dilated with 6-8 $\mathrm{mm}$ CRE balloon and three 10 French plastic stents were placed in the RPS duct (RPSD), RAS duct (RASD) and LHD respectively [Figure 4d].

Subsequently, 3 monthly stent exchanges were performed thrice over the next 9 months and the number of stents in the stent bundle was increased to a maximum number of 5 stents placed at a time. Follow-up contrast-enhanced CT at 6 months confirmed complete resolution of biloma; all stents were removed both from the collection as well as the biliary tree after a total duration of 12 months. The patient has continues to remain asymptomatic on the follow-up, at 15 months after stent removal with normal cholangiogram [Figure 4e].

\section{Discussion}

Bile duct injury (BDI) has been reported in $0.15 \%$ after open

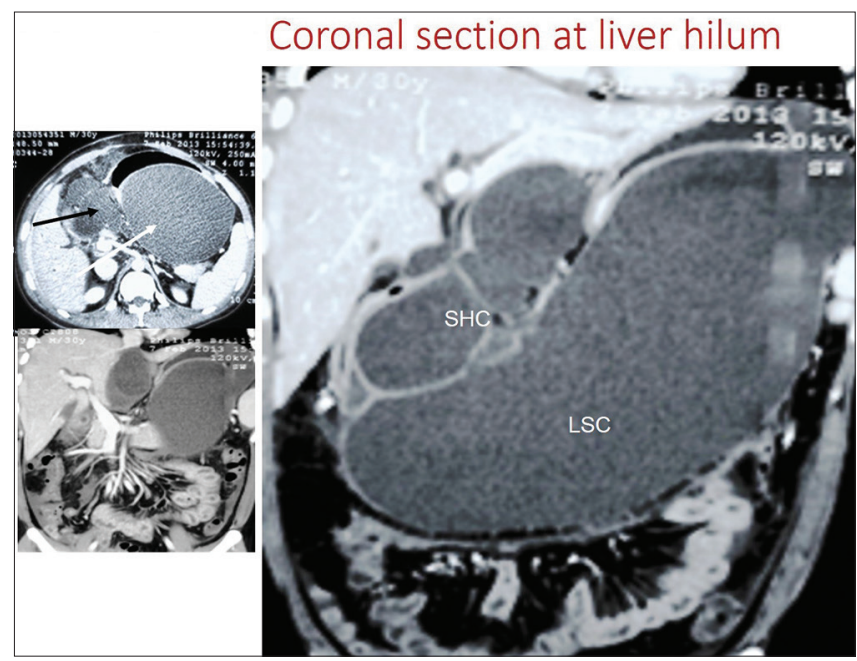

Figure 1: Abdominal computed tomography shows collection in left sub-hepatic space (black arrow) and lesser sac (white arrow) and coronal section showing large lesser sac collection and small left subhepatic collection
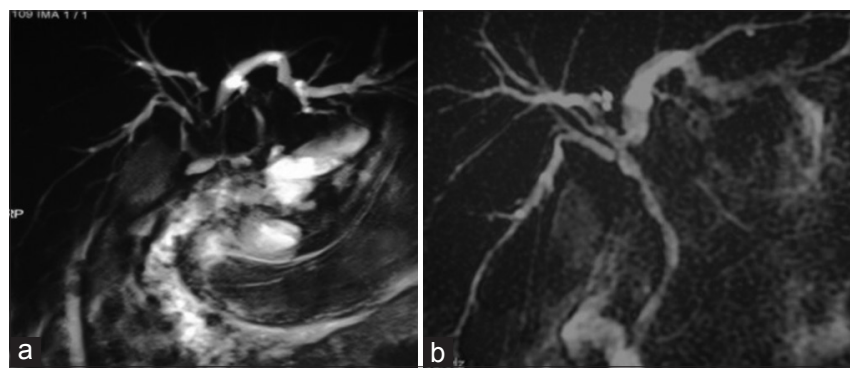

Figure 2: (a) Magnetic resonance cholangiopancreatography shows separation of all ducts and common bile duct not visible. (b) Magnetic resonance cholangiopancreatography after stoppage of bile leak revealed trifurcation at primary biliary confluence with intra-hepatic biliary radicle dilation and narrowing of the proximal common hepatic duct and left hepatic ductal

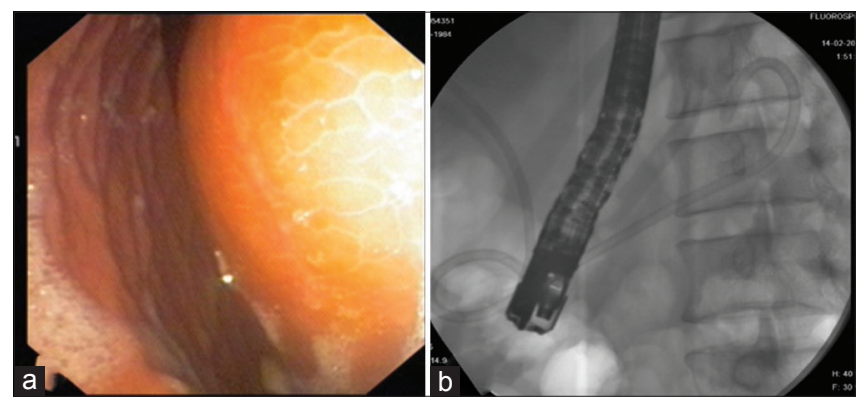

Figure 3: ( $a$ and b) Endoscopic appearance of biloma and placement of double pig tail stent

and in $0.2-0.6 \%$ after laparoscopic cholesytectomy. ${ }^{[3]}$ Major complications reported after BDI, including intra-abdominal bile collections or bilomas and strictures. ${ }^{[3]}$ Bilomas after cholecystectomy are relatively rare and have been reported in up to $2.5 \%$. They usually present with right upper quadrant or epigastric pain, abdominal distention, fever, leukocytosis and extrinsic compression over $\mathrm{BD}$, causing obstructive jaundice, as in our case. ${ }^{[4]}$ Persistent abdominal pain, fever or jaundice after cholecystectomy is a matter of serious concern and 


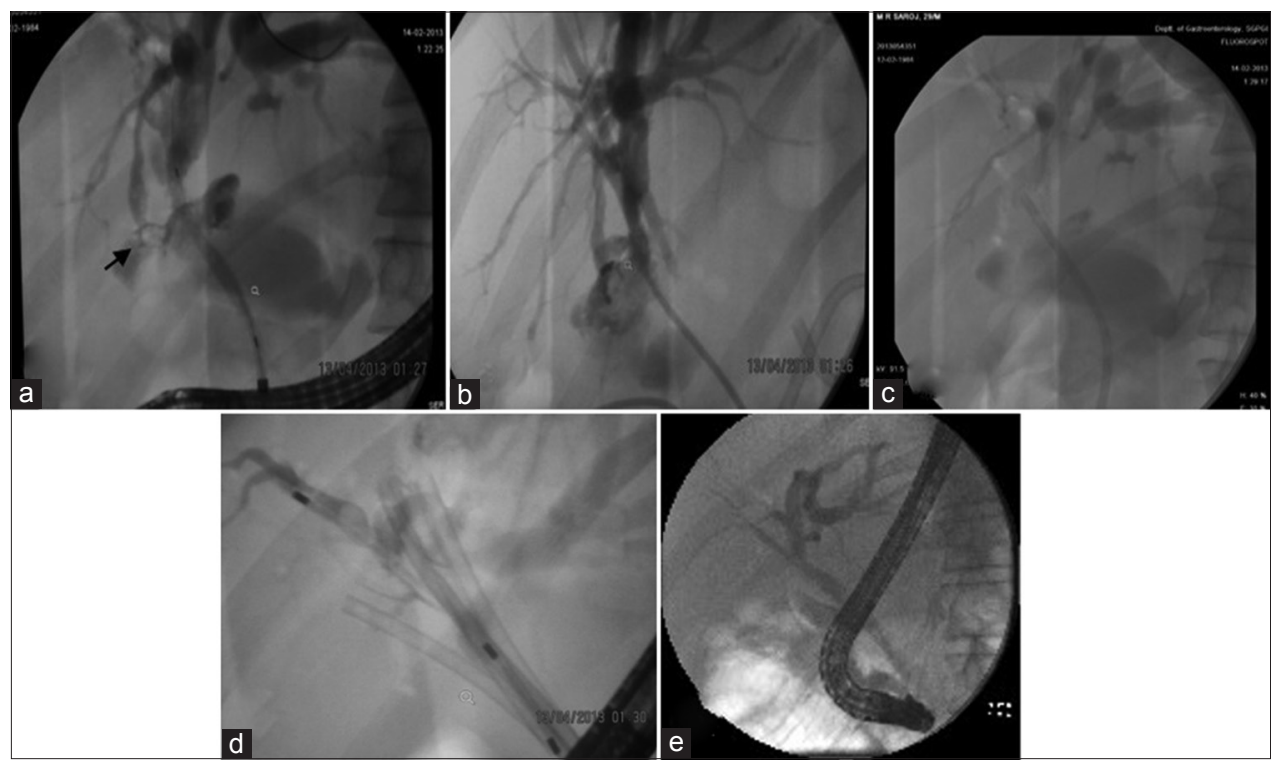

Figure 4: (a-c) Endoscopic retrograde cholangiogram show bile leak (black arrow) and placement of single plastic common bile duct stent. (d) Placement of multiple stents during endoscopic retrograde cholangiopancreatography across common bile duct stricture. (e) Cholangiogram normal biliary system after 15 months of stent removal

should be evaluated adequately, to exclude any intra-abdominal collection or BDI.

BDI have been classified according to Strasberg and Soper et al. (Amsterdam University classification). Initial MRCP [Figure 2a] suggested disconnection of the three major biliary systems (LHD, RASD, RPSD), which is unclassifiable, according to Strasberg. At the time of endoscopic retrograde cholangiopancreatography, dye leakage was noted at the hilum along with opacification of the upstream intra-hepatic biliary ducts, suggesting the possibility of partial continuity of biliary channels [Figure 3a]. We believe that this patient had sustained a Bismuth Type 4 type of injury.

The very large size, the bilocular appearance of the biloma and the absence of bile ascites were points of interest in this patient. We speculate that bile leaking from the injured CHD had been contained within the leaves of the hepatoduodenal ligament and had tracked to the lesser sac, where it accumulated over a period of 6 weeks to produce a massive biloma causing biliary obstruction. There had been no leakage into the general peritoneal cavity by the time the patient presented to the hospital. This speculation is supported by the observation that after endoscopic drainage of the lesser sac bilioma, the smaller loculus, probably a collection in the hepatoduodenal ligament impinging on the lesser curve of the stomach, had resolved pari passu with resolution of the collection in the lesser sac, suggesting that continuity had been maintained between the two loculi.

Holistic management of symptomatic bilomas requires drainage of the collection by placement of a percutaneous catheter and establishing a controlled external biliary fistula, as well as tackling the leakage from the biliary tree responsible for the formation of the biloma. This is usually done by ES and biliary stenting. ${ }^{[5-7]}$ Surgical management of bilomas has been associated with high morbidity. Percutaneous biliary drainage has been reported to be safe and effective for treatment of postoperative bile leaks. ${ }^{[7]}$ Percutaneous drainage of small bilomas may suffice for minor bile leaks that close spontaneously. Endoscopic ultrasound guided drainage with stenting has been used to drain bilomas. ${ }^{[8,9]}$ Combining transmural drainage of a biloma with ES and transpapillary stenting of a bile leak had been reported only once before and succeeded in treating the patient without surgical intervention. ${ }^{[10]}$ To the best of our knowledge, this is the first report of a combined transmural and transpapillary procedure in the same sitting for draining such a large (6 L), symptomatic biloma, followed by endoscopic management of a complex postoperative biliary stricture (separation of all three systems) to complete resolution.

Endoscopic management of postoperative biliary strictures is a well-established procedure today. Major series with long follow periods are now available reporting successful resolution at 8 years in over $90 \%$ and in $80 \%$ at 14 years. Even for Bismuth Type 3 or Type 4 strictures, the success rate is $80 \%$. The key to successful endoscopic management in this patient appears to have been the early initiation of endoscopic therapy, within 6 weeks of BDI. This allowed entry to disconnected biliary systems and stent placement before tight strictures had developed. Subsequent healing of $\mathrm{BDI}$ around the scaffolding provided by the stent bundles, followed by serial (dilatation and) exchange of stent bundles, allowed restoration of near normal caliber to the biliary channels at the end of 1-year. ${ }^{[1]}$ Further follow-up of this patient over the next decade or longer will establish how effective has endo-therapy been. 


\section{Conclusion}

Early endoscopic management using a combined (transgastric and transpapillary) approach, should be considered as an option, in the management of postcholecystectomy large bilomas with bile leak and biliary strictures; to avoid the development of refractory biliary strictures, and the need for more invasive therapeutic procedures which are associated with higher morbidity.

\section{Acknowledgment}

All authors have contributed significantly, and that all authors are in agreement with the content of the manuscript. All authors read the manuscript and approve the manuscript.

\section{Financial support and sponsorship}

Nil.

\section{Conflicts of interest}

There are no conflict of interest.

\section{References}

1. Gould L, Patel A. Ultrasound detection of extrahepatic encapsulated bile: “Biloma”. AJR Am J Roentgenol 1979;132:1014-5.
2. Vazquez JL, Thorsen MK, Dodds WJ, Quiroz FA, Martinez ML, Lawson TL, et al. Evaluation and treatment of intraabdominal bilomas. AJR Am J Roentgenol 1985;144:933-8.

3. Ralph-Edwards T, Himal HS. Bile leak after laparoscopic cholecystectomy. Surg Endosc 1992;6:33-5.

4. Binmoeller KF, Katon RM, Shneidman R. Endoscopic management of postoperative biliary leaks: Review of 77 cases and report of two cases with biloma formation. Am J Gastroenterol 1991;86:227-31.

5. Waage A, Nilsson M. Iatrogenic bile duct injury: A population-based study of 152776 cholecystectomies in the Swedish Inpatient Registry. Arch Surg 2006;141:1207-13.

6. Cozzi G, Severini A, Civelli E, Milella M, Pulvirenti A, Salvetti M et al. Percutaneous transhepatic biliary drainage in the management of postsurgical biliary leaks in patients with nondilated intrahepatic bile ducts. Cardiovasc Intervent Radiol 2006;29:380-88.

7. Barton JR, Russell RC, Hatfield AR. Management of bile leaks after laparoscopic cholecystectomy. Br J Surg 1995;82:980-4.

8. Shami VM, Talreja JP, Mahajan A, Phillips MS, Yeaton P, Kahaleh M. EUS-guided drainage of bilomas: A new alternative? Gastrointest Endosc 2008;67:136-40.

9. Piraka C, Shah RJ, Fukami N, Chathad KV, Chen YK. EUS-guided drainage of intra-abdominal fluid collections and abscesses. Gastrointest Endosc 2009;70:786-92.

10. Baron TH. Combined endoscopic transgastric and transpapillary drainage of an infected biloma. Endoscopy 2006;38:436.

11. Costamagna G, Tringali A, Mutignani M, Perri V, Spada C, Pandolfi M, et al. Endotherapy of postoperative biliary strictures with multiple stents: Results after more than 10 years of follow-up. Gastrointest Endosc 2010;72:551-7. 